\title{
Laparoendoscopic Pfannenstiel Nephrectomy using Conventional Laparoscopic Instruments - Preliminary Experience
}

\author{
Anibal W. Branco, William Kondo, Luciano C. Stunitz, Jarbas Valente, Alcides J. Branco \\ Filho
}

Cruz Vermelha Hospital and Vita Batel Hospital, Curitiba, Parana, Brazil

\begin{abstract}
Purpose: To confirm the feasibility of the laparoendoscopic Pfannenstiel nephrectomy using conventional laparoscopic instruments.

Materials and Methods: Since March 2009, laparoscopic nephrectomy through a Pfannenstiel incision has been performed in selected patients in our service. The Veress needle was placed through the umbilicus which allowed carbon dioxide inflow. One $5 \mathrm{~mm}$ (or $10 \mathrm{~mm}$ ) trocar was placed at the umbilicus for the laparoscope, to guide the placement of three trocars over the Pfannenstiel incision. Additional trocars were placed as follows: a $10 \mathrm{~mm}$ in the midline, a $10 \mathrm{~mm}$ ipsilateral to the kidney to be removed ( $2 \mathrm{~cm}$ away from the middle one), and a $5 \mathrm{~mm}$ contralateral to the kidney to be removed $(2 \mathrm{~cm}$ away from the middle one). The entire procedure was performed using conventional laparoscopic instruments. At the end of the surgery, trocars were removed and all three incisions were united into a single Pfannenstiel incision for specimen retrieval.

Results: Five nephrectomies were performed following this technique: one atrophic kidney, one kidney donation, two renal cancers and one bilateral renal atrophy. Median operative time was 100 minutes and median intraoperative blood loss was $100 \mathrm{cc}$. No intraoperative complications occurred and no patients required blood transfusion. Median length of hospital stay was 1 day (range 1 to 2 days).

Conclusions: The use of the Pfannenstiel incision for laparoscopic nephrectomy seems to be feasible even when using conventional laparoscopic instruments, and can be considered a potential alternative for traditional laparoscopic nephrectomy.
\end{abstract}

Key words: laparoscopy; nephrectomy; Pfannenstiel; transumbilical surgery; minimally invasive surgery

Int Braz J Urol. 2010; 36: 719-23

\section{INTRODUCTION}

Recently, many authors, including ourselves, have successfully described the role of the laparoendoscopic single-site surgery (LESS) by umbilical approach for urological pathologies (1-4). The potential benefits are related to the minimization of skin morbidity (temporary incision pain and muscle spasms, avoidance of epigastric vessel injury) and the improved cosmesis. The use of an alternative location of the incision (Pfannenstiel) for a LESS nephrectomy was recently reported in animal model and humans by Steinway et al. (6) and Ponsky et al. (7), respectively. The aim of this study was to confirm the feasibility of this approach for different indications of laparoscopic nephrectomy using only conventional laparoscopic instruments.

\section{MATERIALS AND METHODS}

Since March 2009, laparoscopic nephrectomy through a Pfannenstiel incision has been performed in 
Laparoendoscopic Pfannenstiel Nephrectomy

Table 1 - Patients' demographics and indications for the procedure.

\begin{tabular}{|c|c|c|c|c|}
\hline & Age (yrs) & Gender & Indication & Previous Surgery \\
\hline Case 1 & 42 & Female & Non-functional right kidney & $\begin{array}{c}2 \text { Cesarean sections } \\
\text { (Pfannenstiel incision scar) }\end{array}$ \\
\hline Case 2 & 48 & Female & $\begin{array}{l}\text { Live-donor nephrectomy } \\
\text { (mother to son) }\end{array}$ & $\begin{array}{c}2 \text { Cesarean sections } \\
\text { (Pfannenstiel incision scar) }\end{array}$ \\
\hline Case 3 & 60 & Male & $\begin{array}{l}5-\mathrm{cm} \text { mass in the middle third of } \\
\text { the left kidney }\end{array}$ & No \\
\hline Case 4 & 62 & Male & $\begin{array}{l}\text { 4.8- } \mathrm{cm} \text { mass in the middle third } \\
\text { of the left kidney }\end{array}$ & No \\
\hline Case 5 & 32 & Female & $\begin{array}{l}\text { End-stage renal failure with } \\
\text { recurrent episodes of acute } \\
\text { pyelonephritis }\end{array}$ & $\begin{array}{c}2 \text { Cesarean sections } \\
\text { (Pfannenstiel incision scar) }\end{array}$ \\
\hline
\end{tabular}

selected patients in our service. All patients signed the informed consent for the surgery. Data were collected prospectively for subsequent analysis. Patient selection was determined by any situation, pathological or not (i.e. kidney donation), for which laparoscopic nephrectomy was deemed appropriate as the standard of care in our practice. The previous history of multiple cesarean sections was not a contraindication for the procedure.

All cases are summarized in Table-1.

\section{SURGICAL TECHNIQUE}

Under general anesthesia, the patient was placed in a 60-degree lateral decubitus position, contralateral to the kidney to be operated. The axilla was protected with a small pillow and the arm was maintained on an armrest in a functional position. The Veress needle was placed through the umbilicus allowing insufflation of the abdominal cavity with carbon dioxide. The pneumoperitoneum was maintained between 10 and $12 \mathrm{mmHg}$. One $5 \mathrm{~mm}$ trocar (or a 10 $\mathrm{mm}$ trocar) was placed in the umbilicus for the laparoscope, to guide the placement of three trocars over the Pfannenstiel incision, avoiding damage to adjacent structures. Trocars were placed as follows: a $10 \mathrm{~mm}$ at the midline, a $10 \mathrm{~mm}$ ipsilateral to the kidney to be removed (two centimeters away from the middle one), and a $5 \mathrm{~mm}$ contralateral to the kidney to be removed (two centimeters far from the middle one). The laparoscope was introduced into the abdominal cavity through the middle port over the Pfannenstiel incision. The surgeon always worked with the trocars placed over the Pfannenstiel incision. There was no need to change the position of the camera during the procedure.

The surgical steps were:

- Mobilization of the colon;

- Identification of the psoas muscle and the ureter;

- Dissection and ligature of the renal vessels;

- Releasing the kidney from its attachments, starting medially, followed by the inferior renal pole and the lateral aspect of the kidney;

- Ligature of the ureter;

- The ureter was held by the assistant close to the diaphragm allowing the posterior and the superior dissection;

- The kidney was placed inside an endoscopic bag;

- All skin incisions were united by a single $6 \mathrm{~cm}$ Pfannenstiel incision and the kidney was retrieved from the abdominal cavity.

The assistant retracted the ureter towards the diaphragm exposing the posterior aspect of the kidney. After releasing the posterior attachments, the upper renal pole could be reached and released.

In the case of live donor nephrectomy, the kidney was first released and then the renal vessels 
and the ureter were ligated, as usually performed in cases for renal transplantation.

\section{RESULTS}

All five procedures were successfully performed using the described technique. We did not use any special instruments or single-port devices in our patients.

Median operative time was 100 minutes (range 80 to 120 minutes), median intraoperative blood loss was $100 \mathrm{cc}$ (range 50 to $100 \mathrm{cc}$ ), and median length of hospital stay was 1 day (range from 1 to 2 days) (Table-2).

In the second case (live donor nephrectomy), the warm ischemia time was 3.5 minutes. The graft presented immediate diuresis. The postoperative course of the recipient was uneventful and the patient was discharged seven days after the transplantation with a creatinine level of $0.9 \mathrm{mg} / \mathrm{dL}$.

The pathological examination of the specimen demonstrated renal atrophy in the first patient, a 5.5 $\mathrm{cm}$ renal cell carcinoma (pT1b) in the third patient, a $4.8 \mathrm{~cm}$ renal cell carcinoma (pT1b) in the fourth patient, and bilateral renal atrophy in the fifth patient.
No intraoperative or postoperative complications occurred in this initial series.

\section{COMMENTS}

Nephrectomy has been performed by minimally invasive surgery using transumbilical laparoendoscopic single-site and hybrid transvaginal approaches (1-5,8). Recently, Ponsky et al. (7) described the first series of LESS nephrectomy and nephroureterectomy performed through a Pfannenstiel incision with no additional ports for renal cancer. In this article, we present our initial experience with this approach using no special devices for different indications of laparoscopic nephrectomy.

In 2008, Gupta et al. (9) compared different locations of incisions (modified iliac fossa and Pfannenstiel incisions) to retrieve the kidney during laparoscopic transperitoneal donor nephrectomy and they found that there was less morbidity associated with the iliac fossa incision. Two patients had bladder injury and 1 patient had bowel injury while making the Pfannenstiel incision. Also, the mean length of the Pfannenstiel incision was longer than the iliac fossa incision $(7.3 \mathrm{~cm}$ vs. $5.8 \mathrm{~cm})$. However, Pfannenstiel

Table 2 - Intraoperative and early postoperative outcomes.

\begin{tabular}{|c|c|c|c|c|c|}
\hline & $\begin{array}{l}\text { Nephrectomy } \\
\text { Side }\end{array}$ & Trocars & $\begin{array}{l}\text { Surgical } \\
\text { Time } \\
(\min )\end{array}$ & $\begin{array}{l}\text { Intraoperative } \\
\text { Bleeding (cc) }\end{array}$ & $\begin{array}{c}\text { Hospital } \\
\text { Discharge } \\
\text { (days) }\end{array}$ \\
\hline Case 1 & $\begin{array}{c}\text { Right } \\
\text { (Figure-1) }\end{array}$ & $\begin{array}{l}\text { Three trocars over the previous Pfan- } \\
\text { nenstiel scar. One additional } 10 \mathrm{~mm} \\
\text { umbilical trocar }\end{array}$ & 80 & 100 & 1 \\
\hline Case 2 & Left & $\begin{array}{l}\text { Three ports placed over the previous } \\
\text { Pfannenstiel scar. One additional } 5 \mathrm{~mm} \\
\text { umbilical trocar }\end{array}$ & 120 & 100 & 1 \\
\hline Case 3 & Left & $\begin{array}{c}\text { Three suprapubic trocars. One } 5 \mathrm{~mm} \\
\text { umbilical trocar }\end{array}$ & 90 & 50 & 2 \\
\hline Case 4 & Left & $\begin{array}{l}\text { Three suprapubic trocars. One } 5 \mathrm{~mm} \\
\text { umbilical trocar }\end{array}$ & 100 & 100 & 1 \\
\hline Case 5 & Bilateral & $\begin{array}{l}\text { Three ports placed over the previous } \\
\text { Pfannenstiel scar. One additional } 5 \mathrm{~mm} \\
\text { umbilical trocar }\end{array}$ & 120 & 100 & 2 \\
\hline
\end{tabular}



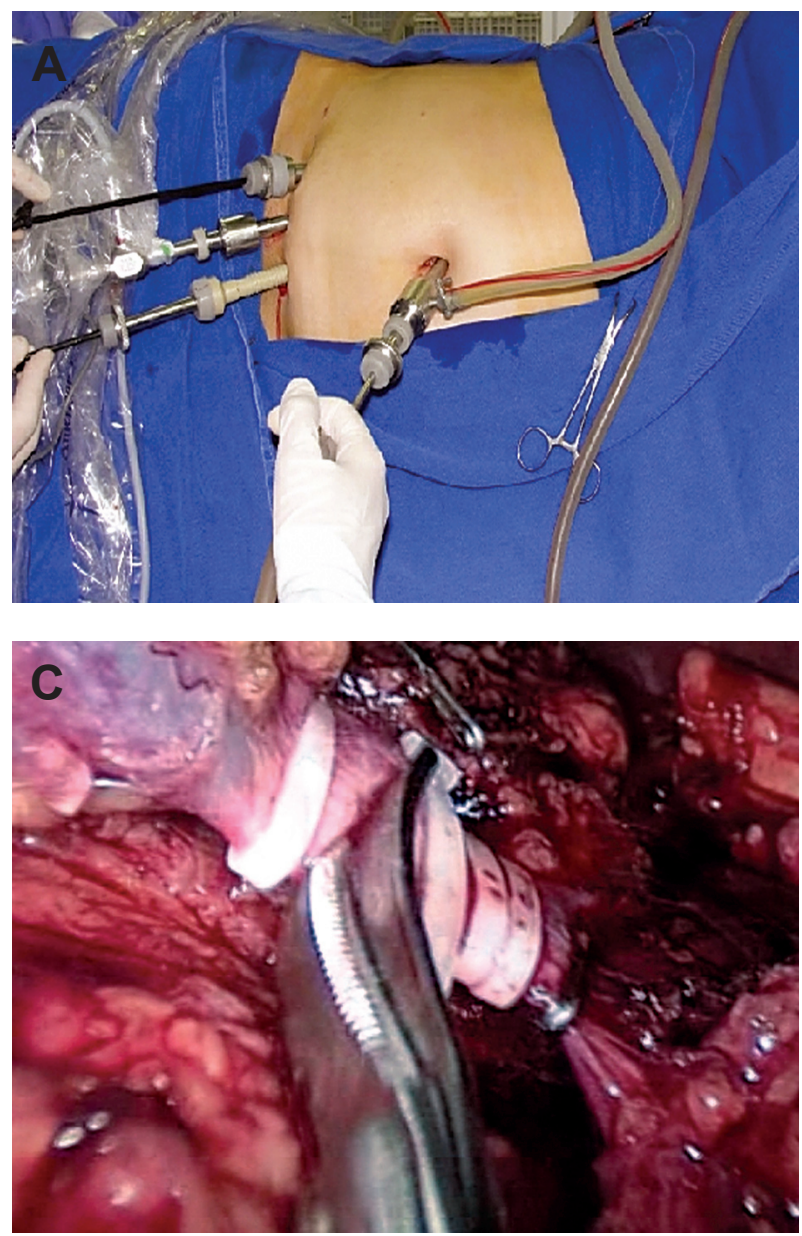

Figure 1 - A) Position of all trocars. B) Cutting the left renal artery. C) Ligature of the left renal vein using Hem-o-lok ${ }^{\circledR}$ clips. D) Final aspect of the scar.

incision was found to be superior in terms of cosmesis.

Considering these risks of bladder and bowel injuries during the performance of the Pfannenstiel incision, we decided to start all our procedures using a transumbilical trocar to guide the placement of the trocars over the Pfannenstiel incision. We did not feel comfortable in placing the suprapubic trocars without the laparoscopic guidance achieved by the umbilical puncture.

Advantages of the Pfannenstiel incision compared to vertical incisions include decreased pain, improved cosmesis (10-12), and better healing. The transverse suprapubic scar can be hidden with most types of clothing, including a bathing suit. In addition, the Pfannenstiel incision may be associ-
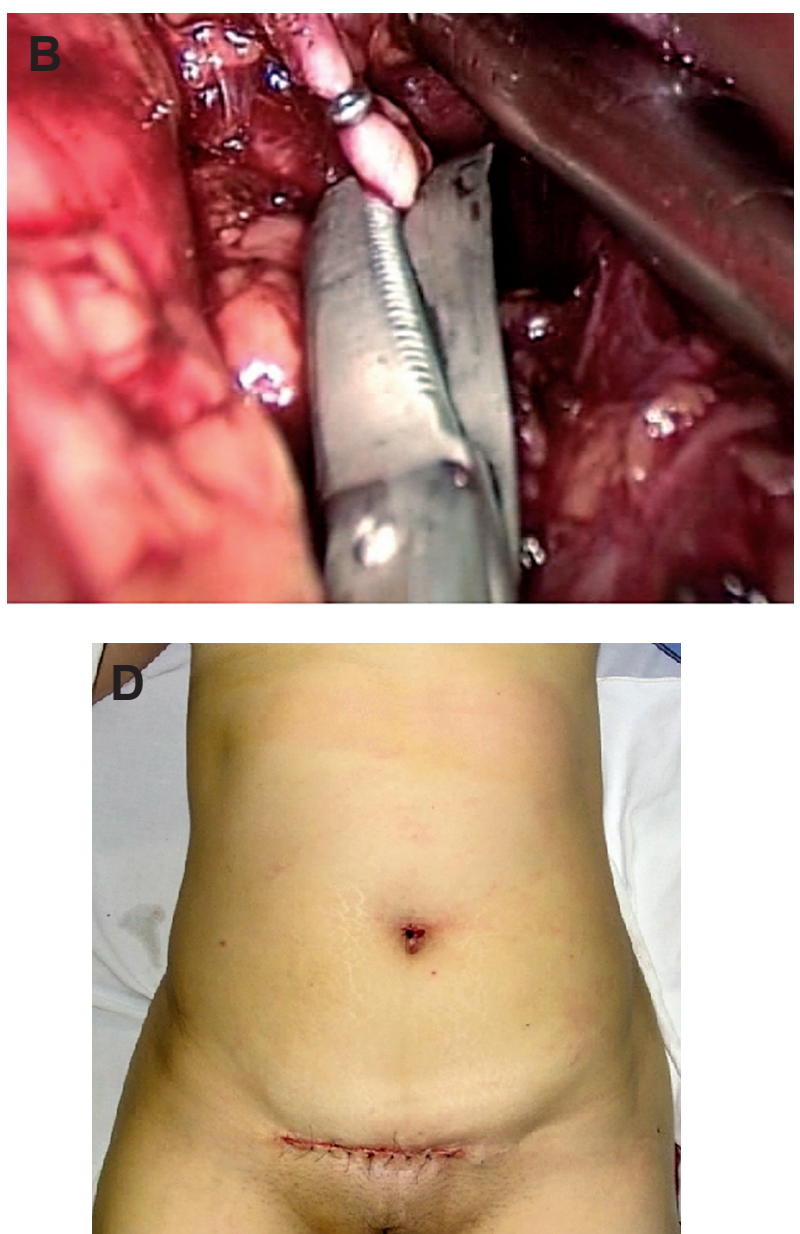
ated with a decreased rate of incisional hernia (12). When Bird et al. (13) analyzed a cohort of patients undergoing laparoscopic radical nephrectomy with intact specimen extraction through 3 different sites (lower quadrant site, umbilical site, and paramedian site), they found that the occurrence of incisional hernia was significantly associated with the paramedian extraction site. Also, cesarean section delivery rates in Brazil are the highest in the world. In 1992, Moraes and Goldenberg (14) found an estimated incidence of cesarean sections of $80.5 \%$ in a Brazilian city. Cesarean rates increased according to income and were higher among women using private health care. Therefore, most Brazilian women already have a Pfannenstiel scar and it is interesting to benefit from an existing incision whenever possible. 
As previously observed by Ponsky et al. (7), the distance from the Pfannenstiel incision to the kidney was not a major challenge during surgery because longer laparoscopic instruments (those used for bariatric surgeries, with $45 \mathrm{~cm}$ working length) were available for the procedure. In their series, Ponsky et al. (7) used extra-long laparoscopic stapling devices to divide the superior renal pole attachments and hilar vessels; however, we confirmed the feasibility of the procedure without using any special devices, which is very interesting to reduce costs of the procedure.

The surgeon must be familiar with the visualization of the structures in a more medial perspective than the standard transperitoneal approach when using the Pfannenstiel LESS (7). This difficulty can be overcome using a 30-degree laparoscope that provides a wider range of viewing angles. Also, the use of the Pfannenstiel incision allows the surgeon to place one trocar $2 \mathrm{~cm}$ away from the other, and this facilitates the movements inside the abdominal cavity when compared to transumbilical LESS, reducing the external clash of the instruments. The umbilical trocar was important during the procedure to facilitate the dissection of the posterior aspect of the kidney and the superior renal pole.

\section{CONCLUSIONS}

In this series, we report our initial experience using the Pfannenstiel incision for laparoscopic nephrectomy with success. Prospective studies are necessary to confirm the real benefits and indications of this alternative surgical approach.

\section{CONFLICT OF INTEREST}

None declared.

\section{REFERENCES}

1. Branco AW, Kondo W, Stunitz LC, Filho AJ, de George MA: Transumbilical laparoscopic urological surgery: are special devices strictly necessary? BJU Int. 2009; 104: 1136-42.

2. Desai MM, Stein R, Rao P, Canes D, Aron M, Rao PP, et al.: Embryonic natural orifice transumbilical endoscopic surgery (E-NOTES) for advanced reconstruction: initial experience. Urology. 2009; 73: 182-7.

3. Gill IS, Canes D, Aron M, Haber GP, Goldfarb DA, Flechner S, et al.: Single port transumbilical (E-NOTES) donor nephrectomy. J Urol. 2008; 180: 637-41; discussion 641.

4. Desai MM, Rao PP, Aron M, Pascal-Haber G, Desai MR, Mishra S, et al.: Scarless single port transumbilical nephrectomy and pyeloplasty: first clinical report. BJU Int. 2008; 101: 83-8.

5. Sanchez-Salas RE, Barret E, Watson J, Stakhovskyi O, Cathelineau X, Rozet F, Galiano M, Rane A, Desai MM, Sotelo R, Vallancien G: Current status of natural orifice trans-endoscopic surgery (NOTES) and laparoendoscopic single site surgery (LESS) in urologic surgery. Int Braz J Urol. 2010; 36: 385400.

6. Steinway ML, Lengu IJ, Cherullo EE, Ponsky LE: Laparoendoscopic single-site (LESS) nephrectomy through a Pfannenstiel incision: porcine model. J Endourol. 2009; 23: 1293-6.

7. Ponsky LE, Steinway ML, Lengu IJ, Hartke DM, Vourganti S, Cherullo EE: A Pfannenstiel single-site nephrectomy and nephroureterectomy: a practical application of laparoendoscopic single-site surgery. Urology. 2009; 74: 482-5.

8. Branco AW, Branco Filho AJ, Kondo W, Noda RW, Kawahara N, Camargo AA, et al.: Hybrid transvaginal nephrectomy. Eur Urol. 2008; 53: 1290-4.

9. Gupta M, Singh P, Dubey D, Srivastava A, Kapoor R, Kumar A: A comparison of kidney retrieval incisions in laparoscopic transperitoneal donor nephrectomy. Urol Int. 2008; 81: 296-300.

10. Grantcharov TP, Rosenberg J: Vertical compared with transverse incisions in abdominal surgery. Eur J Surg. 2001; 167: 260-7.

11. Brown SR, Goodfellow PB: Transverse verses midline incisions for abdominal surgery. Cochrane Database Syst Rev. 2005; 19: CD005199.

12. Tisdale BE, Kapoor A, Hussain A, Piercey K, Whelan JP: Intact specimen extraction in laparoscopic nephrectomy procedures: Pfannenstiel versus expanded port site incisions. Urology. 2007; 69: 241-4.

13. Bird VG, Au JK, Sandman Y, De Los Santos R, Ayyathurai R, Shields JM: Comparison of different 
extraction sites used during laparoscopic radical nephrectomy. J Urol. 2009; 181: 1565-70.
14. de Moraes MS, Goldenberg P: Cesarean sections: an epidemic profile. Cad Saude Publica. 2001; 17: 50919.
Accepted after revision:

June 21, 2010

\author{
Correspondence address: \\ Dr. William Kondo \\ Av. Getulio Vargas, 3163 / 21 \\ Curitiba, PR, 80240-041, Brazil \\ E-mail: williamkondo@yahoo.com
}

\section{EDITORIAL COMMENT}

Nowadays laparoscopists are very interested in reducing skin scars. In this article, at least two or three portal scars could be avoided. In my opinion, the method proposed may be useful when the surgeon intends to remove the kidney without morcellation and in such cases the Pfannenstiel incision is a very good cosmetic option.

This is a hybrid approach that combines an umbilical access for the camera, at the beginning of the procedure, and the "LESS" at the transverse suprapubic skin incision used at the end for removal of the kidney. The initial umbilical port followed the introduction of trocars in the lower abdomen and permitted the introduction of instrument to facilitate the dissection of upper pole and posterior surface of the kidney.

This article has some aspects that should be pointed out as 1. Introduction of trocars at the Pfan- nenstiel incision under endoscopic orientation; 2. No need of any special device other than regular trocars; 3. The trocars can be a little bit more distant than in the LESS umbilical procedure which can facilitate the procedure.

Before the laparoendoscopic Pfannenstiel nephrectomy could be considered more than feasible, its safety, results and complications should be compared to the traditional laparoscopic nephrectomies, exactly as laparoscopic and open nephrectomies was compared.

Dr. Anuar Ibrahim Mitre Associate Professor of Urology University Sao Paulo, USP

Sao Paulo, SP, Brazil E-mail:anuar@mitre.com.br 